\title{
REINVENÇÕES DE PRÁTICAS DE CUIDADO EM TEMPOS DE COVID-19
}

REINVENTIONS OF CARE PRACTICES IN TIMES OF COVID-19 REINVENCIONES DE PRÁCTICAS DE CUIDADO EN TIEMPOS DE LA COVID-19

Marcia Maria Santos da Silva ${ }^{1}$ Osmar Arruda da Ponte Neto ${ }^{2}$ Lielma Carla Chagas da Silva ${ }^{3}$

Noraney Alves de Lima ${ }^{4}$ Maria José Galdino Saraiva ${ }^{5}$ Maria Socorro de Araújo Dias ${ }^{6}$

Palavras-chave: Infecções por coronavírus; Estratégia saúde da família; Promoção da saúde; Educação em saúde; Tecnologia.

Keywords: Coronavirus Infections; Family Health Strategy; Health Promotion; Health Education; Technology.

Palabras clave: Infecciones por coronavirus: Estrategia salud familiar; Promoción de la salud; Educación en salud. Tecnología.

Submetido: $19 / 11 / 20$

Aprovado: $20 / 12 / 20$

Autor(a) para Correspondência: Márcia Maria Santos da Silva

R. Santana do Acaraú, 280 Pedro Mendes Carneiro Sobral - CE CEP: $62030-712$ E-mail: marciamss@yahoo.com.br

\section{RESUMO}

O cenário pandêmico da Covid-19 aportou desafios para a promoção da saúde e gestão do cuidado, pois suscitou a reinvenção das práticas de atenção. Este escrito objetiva descrever e discutir ações realizadas pela Escola de Saúde Pública Visconde de Saboia, com o redimensionamento da atuação das residências multiprofissionais por ela desenvolvidas. Trata-se de um relato de experiência que comporta três ações instituídas por esta escola e operacionalizadas no município de Sobral, Ceará. As estratégias Comunicação Comunitária, Conectados com a Saúde e Plantão Psicossocial intentaram orientar medidas relacionadas à Covid-19 e dar continuidade às ações de promoção da saúde, prevenção e tratamento de agravos, sobretudo àqueles relacionados à saúde mental. A partir dos fundamentos da educação popular, foi potencializada a comunicação em saúde por meio de equipamentos comunitários e plataformas digitais. A produção de material educativo, as parcerias com instituições e rádios comunitárias e a oferta de escuta qualificada às necessidades de saúde mental foram fundamentais. As estratégias contribuíram para a garantia do direito à informação, 0 incremento à comunicação na saúde, a disseminação de conhecimentos e a incorporação das tecnologias digitais nas práticas de cuidado na saúde.

1. Assistente Social. Mestre em Ensino na Saúde (UECE). Coordenadora de Ensino da Escola de Saúde Pública Visconde de Sabóia (ESP-VS).E-mail: marciamss@yahoo.com.br ORCID: http://orcid.org/0000-0001-6534-8196 2. Fisioterapeuta. Mestre em Saúde da Família (UFC). Docente da Escola de Saúde Pública Visconde de Sabóia (ESPVS).E-mail: netoarruda@live.com 0RCID: http://orcid.org/0000-0003-0660-3112

3. Enfermeira. Mestre em Saúde da Família (UFC). Gerente de Pesquisa da Escola de Saúde Pública Visconde de Sabóia (ESP-VS).E-mail: lielma_carla@yahoo.com.br ORCID: https://orcid.org/0000-0002-2688-9309

4. Assistente Social. Mestre em Saúde da Família (UVA/Renasf). Docente da Escola de Saúde Pública Visconde de Saboia (ESP-VS).E-mail: noraneylima@gmail.com ORCID: https://orcid.org/0000-0002-7521-1801

5. Pedagoga. Mestre em Ensino na Saúde (UECE). Coordenadora Pedagógica da Escola de Saúde Pública Visconde de Sabóia (ESP-VS).E-mail: mariajosegaaldinosaraiva@gmail.com ORCID: http://orcid.org/0000-0001-6006-9091

6. Enfermeira. Doutora em enfermagem (UFC). Docente da Universidade Estadual Vale do Acaraú (UVA). Diretora da Escola de Saúde Pública Visconde de Sabóia (ESP-VS). E-mail: socorroad@gmail.com ORCID: https://orcid. org/0000-0002-7813-547X 


\section{ABSTRACT}

The pandemic scenario of COVID-19 brought challenges to health promotion and care management and led to the reinvention of care practices. This study aims to describe and discuss the actions carried out by the Escola de Saúde Pública Visconde de Saboia redimensioning the performance of multiprofessional residences it developed. It is an experience report that includes three actions instituted by this school and operationalized in the municipality of Sobral, Ceará. The strategies Comunicação Comunitária (Community Communication), Conectados com a Saúde (Connected to Health) and Plantão Psicossocial (Psychosocial Working Shifts) tried to guide measures regarding COVID-19 and to continue the health promotion, prevention and treatment of diseases actions, especially those related to mental health. Based on the foundations of popular education, health communication was strengthened through community equipment and digital platforms. The production of educational material, partnerships with institutions and community radio stations, and the provision of qualified listening to mental health needs were essential. The strategies contributed to guarantee the right to information, increase communication regarding health care, disseminate knowledge, and incorporate digital technologies in health care practices.

\section{RESUMEN}

El escenario pandémico de la COVID-19 aportó desafios para la promoción de la salud y gestión del cuidado y suscitó la reinvención de las prácticas de atención. Esta escritura tiene como objetivo describir y debatir las acciones realizadas por la Escuela de Salud Pública Visconde de Saboia con el redimensionamiento de la actuación de las residencias multiprofesionales por ella desarrolladas. Se trata de un relato de experiencia que incluye tres acciones instituidas por esa escuela y operacionalizadas en el municipio de Sobral, Ceará. Las estrategias Comunicação Comunitária, Conectados com a saúde y Plantão Psicossocial intentaron orientar medidas relacionadas a la COVID-19 y dar continuidad a las acciones de promoción de la salud, prevención y tratamiento de agravios, sobre todo aquellos relacionados a la salud mental. A partir de los fundamentos de la educación popular, se fue potencializada la comunicación en salud por medio de equipamientos comunitarios y plataformas digitales. La producción de material educativo, las asociaciones con instituciones y radios comunitarias y la oferta de escucha calificada a las necesidades de la salud mental fueron fundamentales. Las estrategias contribuyeron para garantizar el derecho a la información, incremento a la comunicación en la salud, diseminación de conocimiento e incorporación de las tecnologías digitales en las prácticas de cuidado en la salud.

\section{INTRODUÇÃ O}

Há três décadas, o Sistema Único de Saúde (SUS) se apresenta como referência mundial de atenção à saúde pública, ancorado em uma perspectiva holística de saúde e em princípios que expressam o reconhecimento das desigualdades sociais e da democracia. Estruturado em três níveis de atenção, tem, na Atenção Básica $(A B)$, a referência para 0 reordenamento das redes de saúde, resguardando a Estratégia Saúde da Família (ESF) como principal canal de acesso.

A criação da ESF, em 1994, instaurou a reorientação do modelo assistencial, centralizando o cuidado no indivíduo e na família, por meio de ações individuais e coletivas. Observam-se avanços como a universalização do acesso, a equidade, a integralidade da atenção e o reconhecimento da diversidade territorial como balizadores das ações. Dentre os desafios, figuram: a efetivação da intersetorialidade, a definição de financiamento com base nas necessidades de saúde dos diferentes contextos territoriais e a expansão de processos formativos que contemplem aspectos humanos e sociais, não centrados na doença ${ }^{1}$.

Não obstante, em 2020, os principais desafios que se aportam para a ESF são potencializados pelo alerta epidemiológico mundial, decorrente da pandemia de Covid-19. Em virtude da pandemia, são incentivadas medidas não farmacológicas como estratégia de prevenção à propagação do SARS-CoV-2 (do inglês: Severe Acute Respiratory Syndrome Coronavirus 2). Uma dessas medidas, com relevantes impactos sociais, políticos e econômicos, é o distanciamento social com o fechamento de instituições e a redução de aglomerações para desacelerar o ritmo do contágio e reduzir a pressão sobre os sistemas de saúde ${ }^{2}$.

No Brasil, o Ministério da Saúde (MS) adotou diferentes medidas para intensificar a vigilância, o diagnóstico e o tratamento da Covid-19. Em maio de 2020, definiu o Protocolo de Manejo Clínico do novo coronavírus na Atenção Primária à Saúde (APS), 
estabelecendo ações que alteraram a rotina na ESF: teleatendimento; realização de testes; manejo clínico de sindrome gripal; estratificação de gravidade do caso; notificação e monitoramento clínico ${ }^{3}$.

A redefinição das ações nas Unidades Básicas de Saúde (UBS) trouxe o desafio da promoção da saúde e gestão do cuidado na APS no cenário pandêmico, pois ele modificou a forma de organização dos processos de trabalho na ESF e despertou outros adoecimentos na população, tais como distúrbios do sono e de apetite, quadros de ansiedade e medo.

A necessidade de considerar a experiência singular do adoecimento expressa a importância de a gestão do cuidado ser estruturada a partir de práticas individuais e coletivas, com planejamento de recursos e corresponsabilidade, voltadas tanto para a UBS quanto para o usuário ${ }^{4}$. Do mesmo modo, a promoção da saúde necessita de um processo educativo contínuo, um advocacy e um compromisso mútuo entre gestores, trabalhadores e usuários, na defesa da produção da saúde que considere os determinantes sociais em seu planejamento e a consecução de Objetivos do Desenvolvimento Sustentável, em seus resultados.

No município de Sobral, Ceará, uma importante estratégia utilizada é a potencialização das ações realizadas pela Escola de Saúde Pública Visconde de Saboia (ESP-VS), por meio da atuação de corpo diretivo, pedagógico e discente da Residência Multiprofissional em Saúde da Família (RMSF) e da Residência Multiprofissional em Saúde Mental (RMSM), programas por ela desenvolvidos.

As residências em saúde vêm incorporando ao sistema de saúde tecnologias de cuidado como novas formas de produzir saúde, o que requer maior aproximação com o território, curiosidade e criatividade. Assim, as residências operam na perspectiva de construir o novo e de trazer inovações para as práticas em saúde. Em face do período

\section{"A redefinição das ações nas Unidades Básicas de Saúde (UBS) trouxe o desafio da promoção da saúde e gestão do cuidado na APS no cenário pandêmico"}

pandêmico, elas passaram por um redimensionamento do escopo das atividades, com a intensificação de ações de promoção da saúde, muitas delas mediadas por tecnologias hard por meio de recursos tecnológicos (internet, redes sociais, dispositivos móveis), que resultaram em um complexo de tecnologias leves de cuidado correlatas aos aspectos biológicos, sociais, psicológicos e culturais que acometeram a população sobralense frente à Covid-19.

\section{METODOLOGIA}

Este escrito se trata de um estudo descritivo, do tipo relato de experiência, desenvolvido no período de março a julho de 2020. As informações apresentadas traduzem a vivência de três estratégias que são parte de um plano de ação integrada da ESPVS durante a pandemia, no município de Sobral-CE, idealizadas e operacionalizadas por seu grupo gestor juntamente com os programas de RMSF e RMSM.

A instituição de medidas com foco no distanciamento social pela gestão local tencionou uma nova dinâmica de trabalho e de vida da população. Ao setor da saúde coube o desafio de gerir as ações de cuidado em saúde e, principalmente, orientar a população sobre os cuidados a serem adotados nesse período. Os Centros de Saúde da Família (CSF), reconhecidos pelo grande fluxo de pessoas, pelo atendimento clínico-assistencial e pelas ações de promoção da saúde, tiveram que limitar a circulação em seus espaços. A população ficou restrita aos limites físicos de suas residências, requerendo a reinvenção de cuidados, muitos deles a serem desenvolvidos de forma remota.

Ciente de seu compromisso com a saúde pública, a ESP-VS definiu ações que respondessem às necessidades de saúde da população. Desse modo, produziu, de forma colaborativa, um plano de ação integrada de educação em saúde e formação de trabalhadores, tomando como premissa a validação dos valores de defesa do SUS e prevenindo, a partir de uma efetiva orientação aos trabalhadores e à população, o colapso dos serviços de saúde por situações evitáveis.

Alicerçada na leitura dos contextos epidemiológicos e sociais que despontavam e suas múltiplas determinações, a ESP-VS implementou três estratégias: Comunicação Comunitária, Conectados com a Saúde e Plantão Psicossocial, com o propósito de orientar a população sobre as medidas protetivas em relação à Covid-19, dar continuidade às ações de 


\section{"As estratégias \\ Comunicação Comunitária, Conectados com a Saúde e Plantão Psicossocial mostraram-se potentes na educação em saúde"}

promoção da saúde e atender às novas demandas que se tornaram emergentes. Desta feita, recorreu-se aos princípios teóricos e metodológicos da educação popular em saúde na produção e disseminação de recursos educativos, a exemplo de spots, paródias e cartilha eletrônica, os quais foram incorporados às estratégias desenvolvidas.

A fim de garantir que as orientações chegassem a todos os grupos populacionais, sobretudo àqueles sem acesso às mídias digitais ou rede de internet, a Comunicação Comunitária buscou informar a população, utilizando linguagem popular, por meio de rádios comunitárias, rádio local e bicicletas sonoras. Para a operacionalização do Conectados com a Saúde e do Plantão Psicossocial, utilizaram-se as plataformas digitais do Instagram e Facebook da ESP-VS, a fim de propagar conteúdos informativos e educacionais; além disso, eram realizadas, diariamente, lives educativas com residentes e educadores populares em saúde, mediadas por docentes. Também, por meio dessas mídias, era garantido o atendimento virtual aos internautas que manifestavam necessidades de cuidado em saúde mental.

Foram definidos, como dispositivos de monitoramento, o registro das informações, a produção de relatórios e o compartilhamento desses em encontros sistemáticos para a análise dos resultados alcançados e redimensionamento das ações.

\section{RESULTADOS E DISCUSSÃO}

Dadas as restrições à realização de atividades presenciais no CSF e o agravamento da pandemia, as estratégias Comunicação Comunitária, Conectados com a Saúde e Plantão Psicossocial mostraram-se potentes na educação em saúde, na ampliação e garantia do acesso às orientações sobre a prevenção e o tratamento da Covid-19 e outros agravos pré- existentes, bem como na produção de modos de vida mais saudáveis. Na perspectiva da garantia do direito à informação em saúde, tais estratégias se complementam com o propósito de alcançar diferentes perfis sociais, levando as informações sobre os cuidados em saúde que coadunem para o empoderamento dos usuários, de modo a promover a corresponsabilidade e o autocuidado.

\section{Comunicação Comunitária: garantia de acesso à informação como direito à saúde}

A gravidade da pandemia está associada à intensificação das desigualdades sociais e dos cortes no financiamento das políticas públicas, próprias da crise do mundo neoliberal. Santos ${ }^{5}$ defende que a pandemia de Covid-19, apesar de cruel, pode representar uma via pedagógica, se considerarmos que provoca reflexões e deixará importantes lições para as sociedades. A pedagogia da Covid-19 exigiu mudanças drásticas em nossos cotidianos, mostrando, por outro lado, que há alternativa ao modo de vida imposto pelo hipercapitalismo.

Para minimizar os impactos da pandemia nesse contexto de desigualdades, buscaram-se estratégias de comunicação em saúde acessiveis à população vulnerável, para promover o seguimento das medidas preventivas de higiene, isolamento, autocuidado e cuidado domiciliar. Optou-se pela Comunicação Comunitária para disseminar informações nos territórios da ESF em situação de extrema pobreza e maior risco de aumento da doença, sendo identificados nove territórios nessas condições.

A Comunicação Comunitária se baseia nos princípios da comunicação popular para abordar conteúdos de interesse público no desenvolvimento de ações nas áreas de educação, cultura, saúde e cidadania. Diante da escassez de recursos para o financiamento do SUS, essa se afirma como uma estratégia viável, pois é caracterizada por não ter fins lucrativos e por ser trabalhada de forma orgânica em âmbito local, mobilizando a participação na transformação do cotidiano das comunidades ${ }^{6-7}$.

Fundamentada nos princípios e diretrizes do SUS, da ESF, das Políticas Nacionais de Promoção da Saúde ${ }^{8}$ e de Educação Popular em Saúde ${ }^{9}$, foi realizada uma escala de atuação dos residentes, identificados pelos docentes, conforme perfil de aproximação com atividades voltadas à comunicação em saúde. As ações desenvolvidas compreenderam: a) mapeamento dos meios de comunicação de massa 
e alternativos; b) produção de áudios educativos/ informativos sobre as medidas de prevenção ao novo coronavírus para os segmentos populacionais vulneráveis (idosos, crianças, adolescentes/jovens); c) articulação interinstitucional e comunitária para a divulgação de spots educativos nos meios de comunicação mapeados.

A fim de identificar os potenciais parceiros na difusão das informações, realizou-se um mapeamento que resultou no apoio de oito rádios, cinco radiadoras paroquianas, uma caixa de som, três bicicletas sonoras, cinco carros de som, nove gerentes de CSF, um diretor de escola pública, três radialistas e três lideranças comunitárias dos territórios.

Esse levantamento foi estratégico para o trabalho intersetorial, que é um importante aliado em ações que busquem a promoção de impactos positivos nas condições de vida das comunidades. Ele oportuniza a articulação de saberes e vivências diversas, criando canais para intervir de maneira efetiva nas situações-problema que afligem as comunidades, com maiores chances de obter resultados satisfatórios e sustentáveis em nível local ${ }^{10-12}$.

Realizaram-se dez visitas institucionais para a apresentação da estratégia em nove CSF e uma escola municipal, com a articulação para divulgar os spots nos territórios. Nos CSF, a divulgação ocorreu através de uma caixa de som nas salas de espera e nos grupos de WhatsApp da unidade. Na escola, as informações foram propagadas para docentes, discentes e gestores por meio do aplicativo WhatsApp, que permite a interação e a capilaridade na comunidade, como um canal de comunicação ${ }^{13}$ entre gestores e trabalhadores, docentes, discentes e população local.

A produção de material educativo contemplou 15 spots divulgados nas mídias comunitárias (radiadoras) acerca das seguintes temáticas: cuidados de higiene, saúde bucal, alimentação saudável e Covid-19 (prevenção, sinais, sintomas e tratamento, isolamento e distanciamento social, uso de máscaras de proteção individual, critérios para realização de teste rápido e monitoramento de casos suspeitos).

Nesse contexto pandêmico, vivencia-se uma situação inédita, em que a necessidade informacional se mostra imperiosa. A ausência de informações impossibilita às pessoas as condições para cuidarem de sua saúde, sobretudo os mais vulneráveis. Ao produzir os materiais educativos, fomentou-se 0 empoderamento dessas pessoas, aqui compreendido

\section{"A prevenção e o cuidado se fazem mais viáveis em redes que atuam nos territórios existenciais"}

como o processo pelo qual os que detêm o poder, no caso, os profissionais de saúde, favorecem os outros (usuários) na aquisição e uso do poder necessário (empoderamento da informação) para tomar decisões que afetam a si ou sua vida ${ }^{14}$.

Reafirma-se a premissa de que a prevenção e 0 cuidado se fazem mais viáveis em redes que atuam nos territórios existenciais ${ }^{15}$ com o reconhecimento das redes locais de comunicação em saúde, demarcando a presença significante de lideranças juvenis e comunicadores, os quais protagonizam ações de comunicação pela cidadania, solidariedade e promoção da saúde em interlocução com as equipes da ESF.

Embora em um contexto de franca valorização e priorização das tecnologias digitais, a Comunicação Comunitária se evidenciou como potente estratégia de garantia do acesso à informação em territórios socialmente desfavorecidos. Segundo Mendes ${ }^{16}$, essas tecnologias afetam o modo como nos comunicamos e influenciam nossas práticas sociais; contudo, a cultura da era digital não exclui as culturas oral, escrita, impressa, de massa e das mídias. Ela se complementa com outras alternativas naqueles segmentos que não dispõem de acesso às mídias digitais como recurso informativo, a exemplo da Comunicação Comunitária.

\section{Educação em saúde por meios digitais: conectando informação, saúde e autocuidado}

Ao considerar que a Política Nacional de Atenção Básica (PNAB) aponta, dentre as atribuições da ESF, a realização de ações de educação em saúde à população adstrita, conforme planejamento da equipe, com abordagens adequadas às necessidades desse público ${ }^{17}$, bem como a imperiosidade de reinvenção de processos de trabalho e de práticas de cuidado, buscou-se desenvolver novas abordagens de educação em saúde.

Morosini, Fonseca e Pereira ${ }^{18}$ destacam que a 
educação em saúde correlaciona a educação e a saúde, ancorada no pensamento crítico sobre a realidade, como uma forma de transformação das condições objetivas que levem à promoção da saúde como direito de todos os sujeitos. Ela engloba, porém não se limita à informação em saúde e apresenta importante potencial contributivo, com maior significação quando estamos frente a temas recémdifundidos no contexto acadêmico e comunitário, a exemplo da pandemia de Covid-19.

Outrossim, emerge, em paralelo à propagação do novo coronavírus, outro tipo de surto que também apresenta risco potencial à saúde pública e foi nominado pela Organização Mundial da Saúde (OMS) de infodemia. Esse conceito contempla a difusão massiva de desinformação sobre a pandemia, comprometendo o acesso a dados com respaldo científico e de autoridades sanitárias. Além das notícias falsas, conhecidas como fake news, também pode aturdir as pessoas o acelerado e volumoso crescimento de informações, nem sempre precisas ${ }^{19}$.

Dentre as ações desenvolvidas com vistas a garantir que a educação em saúde aconteça, utilizando os meios possiveis, está contemplada a estratégia "Conectados com a Saúde", por meio da postagem de materiais educativos no Instagram e da realização de lives, que, de forma interativa e dialógica, orienta sobre diversos assuntos que repercutem no cotidiano das pessoas, com ênfase na promoção da saúde, prevenção de agravos e estímulo ao autocuidado.

As lives foram organizadas de forma temática, sendo mediadas por docentes, conduzidas por residentes e membros do Grupo de Trabalho de Arte e Educação Popular em Saúde da ESP-VS. Os temas eram definidos a partir das possibilidades de contribuição dos núcleos de saberes, tanto em relação à Covid-19 quanto à promoção de estilos de vida mais saudáveis, contemplando aspectos de interesse social, econômico, educacional e de promoção da saúde física e mental.

Considerando a Política Nacional de Promoção da Saúde (PNPS), que tem como um de seus objetivos estimular alternativas inovadoras e socialmente inclusivas/contributivas no âmbito das ações de promoção da saúde ${ }^{8}$, vislumbrou-se que a educação em saúde por mídias digitais, além de inovadora, ao abrir um leque de possibilidades que os recursos tecnológicos permitem, tem um fator inclusivo que pode ser evidenciado pela democratização do acesso às informações, devendo ser utilizada como uma

\section{"As mídias e as plataformas não são apenas mediadoras ou espaços separados do cotidiano, integram a vida e são atores sociais que participam das ações cotidianas"}

importante aliada à promoção da saúde.

As novas mídias, em especial as mídias sociais, trazem possibilidades de interação nunca experimentadas, eliminando barreiras físicas e temporais, proporcionando espaço para novas formas de mobilização social. Um instrumento, portanto, que pode garantir maior alcance de informações essenciais à sociedade, no que diz respeito à sua saúde ${ }^{20}$. Ainda nesse sentido, as mídias e as plataformas não são apenas mediadoras ou espaços separados do cotidiano, integram a vida e são atores sociais que participam das ações cotidianas. Nesse interim, o enfoque passa a ser na cultura e no uso de tais ferramentas, dispositivos e plataformas ${ }^{21}$.

De modo geral, as lives foram operacionalizadas no formato de entrevistas, com roteiro prévio elaborado pelos convidados e revisado por mediadores. Tiveram duração média de 30 minutos, nos quais os profissionais, com linguagem clara e acessivel, sistematizavam informações e orientações temáticas, possibilitando aos participantes a interação ao vivo por meio de comentários, bem como que tirassem suas dúvidas sobre as informações compartilhadas e/ou contribuíssem com as discussões, a partir de seus saberes prévios. Ademais, os vídeos gravados ficaram disponiveis para acesso posterior.

Foram realizadas 122 lives com média de 100 visualizações cada, quando somadas as visualizações ao vivo e do vídeo gravado disponibilizado no IGTV. As temáticas abordadas nas postagens e nas lives contemplaram práticas corporais, orientações nutricionais, prevenção de arboviroses, enfrentamento da Covid-19, cuidados em saúde mental, prevenção e redução do uso abusivo de álcool e outras drogas, saúde e direitos do trabalhador, prevenção de violências, arte e educação popular, dentre outras.

Destaca-se que a articulação de um trabalho interprofissional e multiprofissional proporciona 
complementação dos saberes, assim como possibilita a oferta de um cuidado interdisciplinar e resolutivo voltado para as necessidades de saúde da população².

Acredita-se que a diversificação das temáticas contribuiu para a integralidade, impactando positivamente em vários aspectos da vida das pessoas, assim como de públicos diferentes. Mattos ${ }^{23}$ discutiu os vários sentidos da integralidade, pensados como críticas à realidade e como possibilidade de acesso mais igualitário e solidário ao SUS. Dentre esses sentidos, o autor definiu a integralidade como uma atitude, uma prática que vislumbra superar a visão fragmentada do sujeito. Abordar os assuntos que circundam o cotidiano das pessoas faz interface com os diversos aspectos que interferem nos modos de vida e na saúde.

Dentre as potencialidades na utilização dessa estratégia, são enfatizados: o alcance de pessoas que a rede social Instagram possibilita, sendo popular especialmente entre adultos jovens, com milhões de usuários no Brasil; a interação proporcionada por ser ao vivo, permitindo a realização de comentários em tempo real; o baixo custo; a forma de arquivo do conteúdo produzido, ficando o mesmo disponível na rede social para que as pessoas possam assistir em outros horários e possibilitando compartilhamento com outros indivíduos de forma rápida e prática.

Entretanto, alguns aspectos necessitam ser considerados, tais como a restrição do alcance dessa estratégia às pessoas que possuem conta na rede social Instagram e a limitação do acesso a smartphones ou computadores com internet. A sociabilidade digital é uma realidade por meio da incorporação de novas tecnologias, as quais necessitam de investimento e aprimoramento para serem utilizadas como forma de alcance da comunicação. Nessa perspectiva, estratégias de cuidado mais direcionadas e individualizadas se apresentam como promissoras, a exemplo do apoio psicossocial mediado por essas tecnologias.

\section{Plantão Psicossocial: redimensionamento do cuidado em saúde mental}

Dentre os impactos oriundos de crises epidemiológicas de proporção mundial, merecem especial atenção aqueles que afetam a dimensão subjetiva das pessoas. Os abalos na saúde mental das populações se alastram e decorrem das intensas mudanças nas rotinas individuais e coletivas necessárias nesses contextos e das angústias

\section{"A sociabilidade digital é uma realidade por meio da incorporação de novas tecnologias"}

geradas pelo medo de contaminação, morte, perda de parentes, problemas econômicos e incertezas quanto ao futuro ${ }^{24}$.

0s episódios de pandemia tendem a deixar rastros socioemocionais em quase metade das pessoas que os vivenciam. Nas situações em que não são traçadas alternativas de intervenção para as reações dela decorrentes, é possivel que se manifestem psicopatologias a elas relacionadas. É mister, portanto, que se viabilizem canais de cuidado que possam proteger e promover o bem-estar psicossocial e o cuidado em saúde mental ${ }^{25}$.

Com fulcro na necessidade de promover uma escuta qualificada da população em relação aos seus medos, anseios, dentre outros agravantes que o cenário pandêmico trouxe, e com vistas à garantia do cuidado individualizado, foi instituído o Plantão Psicossocial. Partindo da escuta das equipes da ESF, elaborou-se uma proposta de atenção à saúde mental, por meio do acolhimento das necessidades que poderiam surgir, a exemplo da ansiedade, complicações associadas às tentativas de suicídio, raiva, estresse, entre outras queixas que causam comprometimento significativo do funcionamento social e cotidiano, e que foram comuns durante períodos de isolamento social.

A princípio, foi realizado o planejamento sobre as formas de acesso da população ao Plantão Psicossocial e, considerando o alcance das mídias digitais, optou-se pela utilização das redes sociais digitais da ESP-VS: Instagram e Facebook. Outros aspectos necessários à operacionalização do Plantão Psicossocial foram tomados em consideração, tais como: dias, horários e categorias profissionais participantes. Foram direcionados psicólogos e assistentes sociais das residências, que ficaram virtualmente disponíveis para os atendimentos de segunda-feira a domingo, das $7 \mathrm{~h}$ às $21 \mathrm{~h}$.

0 s profissionais foram organizados em equipes compostas por ambas as categorias, em turnos de 
atendimento pré-definidos. Para facilitar o acesso ao Plantão Psicossocial e informar a disponibilidade do serviço, foram traçadas estratégias como a elaboração de um banner digital com as informações sobre o objetivo, dias e horários de funcionamento; divulgação desse banner nas redes sociais da prefeitura e da Secretaria de Saúde; compartilhamento das informações em grupos de WhatsApp dos CSF e demais grupos privados.

Para a realização dos atendimentos via Facebook, foram criadas três caixas de diálogos, cujos links foram disponibilizados na própria rede social e amplamente divulgados em outros canais, como em grupos de WhatsApp. No Instagram, os atendimentos foram realizados por meio da ferramenta do direct, possibilitando à população o envio de mensagens de forma privada ao perfil da ESP-VS. A partir do contato realizado, a conversa era sinalizada pelo profissional que fez o primeiro contato, passando esse a ser o único a acessá-la, a fim de manter o sigilo do atendimento.

A realização de atendimentos de forma virtual instigou diálogos sobre a necessária preponderância da postura ética por parte de todos os profissionais envolvidos no Plantão Psicossocial. Essa reflexão ganhou novos contornos por diferir das práticas presenciais, cujo respeito ao sigilo remete, de maneira prioritária, a elementos concretos como a estrutura da sala e a atenção com documentos. No meio virtual, o sigilo demanda de uma relação intrínseca com a ética e a corresponsabilidade do profissional e usuário quanto ao respeito e à proteção das informações compartilhadas ${ }^{26}$.

No curso da ação foram necessárias estratégias complementares que contribuíram na qualificação do atendimento virtual e do cuidado prestado. Dentre elas, constam: a elaboração de um roteiro de avaliação das pessoas que procuram o Plantão Psicossocial; a garantia de retorno das pessoas atendidas, como uma estratégia de vínculo e continuidade do cuidado; o estabelecimento de parcerias com outros setores das políticas públicas, com vistas à maior divulgação do Plantão Psicossocial para alcance da população periférica; o compartilhamento de casos com a ESF para questões clínicas e sociais emergidas nos atendimentos; a articulação com as equipes dos Centros de Atenção Psicossocial (CAPS) II e de Álcool e outras Drogas para a discussão e seguimento dos casos mais graves; e a redefinição de fluxos de atendimento junto à Rede de Atenção Integral à Saúde Mental (RAISM).

\section{"As mudanças advindas da pandemia de Covid-19 instigaram os profissionais da saúde a reinventar práticas $e$ produzir formas variadas de cuidado"}

Foram realizados 380 atendimentos, sendo as principais queixas relatadas: sintomas de ansiedade, o medo gerado pela insegurança frente ao desconhecido e conflitos familiares que podem ter sido gerados ou potencializados pela pandemia. Constatou-se a ampla abrangência geográfica do município e a prevalência do acesso por adolescentes e adultos jovens do sexo feminino. Também foi verificada a recorrência de atendimentos para uma mesma pessoa.

Destacam-se como entraves identificados no decorrer da efetivação dessa estratégia: a falta de acesso de parte da população aos meios tecnológicos de comunicação e à internet; $a$ inabilidade de parte da população para o manejo dos aplicativos utilizados; os imprevistos relacionados à qualidade de conexão da internet; a imprevisibilidade do tempo de duração e a descontinuidade do atendimento.

A experiência possibilitou vivenciar, por meios digitais, o acolhimento, a escuta e o diálogo, sistematizados por meio do Plantão Psicossocial, enquanto tecnologia leve de cuidado ${ }^{27}$. Sobressaiuse como elemento estruturante a relação entre profissionais e usuários, produzindo diferentes formas de cuidar.

\section{CONCLUSÃO}

As mudanças advindas da pandemia de Covid-19 instigaram os profissionais da saúde a reinventar práticas e produzir formas variadas de cuidado, sob o prisma da integralidade, em condições adversas. Nesse desafio, a experiência vivenciada pela ESP-VS investiu esforços na interface entre as tecnologias digitais e as tecnologias leves de cuidado, com resultados que possibilitaram vislumbrar novos paradigmas na atenção à saúde.

A integração de gestores, docentes e discentes nas ações possibilitou leituras ampliadas sobre os 
cenários de saúde. Embora afetados pelo súbito impacto dos riscos e perdas provocados pela pandemia, oportunizou-se o fortalecimento da resiliência, revelando talentos e potencialidades criativas com o desenvolvimento de novas habilidades no uso de tecnologias digitais para a produção de modos de cuidar.

As estratégias desenvolvidas se complementam na busca da universalidade do acesso, da integralidade, do cuidado e da equidade na atenção à saúde. Elas evidenciaram que as tecnologias possibilitam uma interação dialógica, eliminando barreiras físicas e temporais, potencializando o alcance do acesso às informações, a construção de conhecimentos e a multiplicação das informações para a promoção da saúde.

Apontamos que as estratégias desenvolvidas no enfrentamento da Covid-19, em tempos de distanciamento social, necessitam ser inovadoras e possibilitar apoio, comunicação, afeto, produção e disseminação de conhecimentos. Nesse sentido, ousou-se agregar elementos de distintas linguagens, na busca por mobilizar e integrar saberes tecnológicos e da educação popular com fito no alcance de diferentes perfis socioculturais da população.

\section{CONTRIBUIÇÃO DOS AUTORES}

Marcia Maria Santos da Silva contribuiu com redação, análise e revisão crítica do manuscrito. Osmar Arruda da Ponte Neto contribuiu com redação, análise e revisão crítica do manuscrito. Lielma Carla Chagas da Silva contribuiu com redação, análise e revisão crítica do manuscrito. Noraney Alves de Lima contribuiu com redação, análise e revisão crítica do manuscrito. Maria José Galdino Saraiva contribuiu com redação, análise e revisão crítica do manuscrito. Maria Socorro de Araújo Dias contribuiu com redação, análise e revisão crítica do manuscrito.

\section{REFERÊNCIAS}

1. Arantes LJ, Shimizu HE, Merchán-Hamann E. Contribuições e desafios da Estratégia Saúde da Família na Atenção Primária à Saúde no Brasil: revisão da literatura. Cien Saude Colet [serial on the internet]. 2016 [cited 2020 Jul 16];21(5):149909. Available from: https://www.scielo.br/pdf/csc/ v21n5/1413-8123-csc-21-05-1499.pdf -

2. Organização Pan-americana de Saúde. Considerações sobre medidas de distanciamento social e medidas relacionadas com as viagens no contexto da resposta à pandemia de COVID-19 [document on the internet]. Washington: OPAS; 2020 [cited 2020 July 16]. Available from: https:// iris.paho.org/bitstream/handle/10665.2/52045/

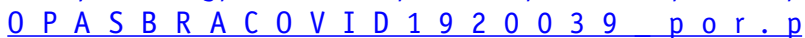
$\mathrm{df}$ ? sequence $=9$

3. Brasil. Protocolo de Manejo Clínico do Coronavírus (COVID-19) na Atenção Primária à Saúde. Brasília: Ministério da Saúde; 2020.

4. Grabois V. Gestão do cuidado. In: Gondim R, Grabois V, Mendes Junior WV, organizadores. Qualificação dos Gestores do SUS. 2. ed. Rio de Janeiro: Fiocruz/ENSP/EAD; 2011. p. 153-190.

5. Santos BS. A Cruel Pedagogia do Vírus. Coimbra: Edições Almedina, S. A.; 2020.

6. Peruzzo VMK. Conceitos de comunicação popular, alternativa e comunitária revisitados e reelaborações no setor. ECO-Pós [serial on the internet]. 2009 [cited 2020 July 25];12(2):46-61. Available from: https://revistas.ufrj.br/index.php/eco pos/article/ download/947/887

7. Zanchett SA. Reflexões sobre comunicação popular e comunitária: Uma análise a partir das estratégias de comunicação de CPT/MS. Passagens UFC (Online) [serial on the internet]. 2015 [cited 2020 July 25];6(2). Available from: http://www.periodicos.ufc.br/index.php/ passagens/article/view/2475

8. Brasil. Política Nacional de Promoção da Saúde - PNPS: Anexo I da Portaria de Consolidação n. 2, de 28 de setembro de 2017. Brasília: Ministério da Saúde; 2018.

9. Brasil. Portaria $n^{0}$ 2.761, de 19 de novembro de 2013. Institui a Política Nacional de Educação Popular em Saúde, no âmbito do Sistema Único de Saúde (SUS) [serial on the internet]. Diário Oficial da União, Brasília; (2013 Nov 19 [cited 13 0ct 2020]). Available from: https://bvsms.saude.gov.br/ bvs/saudelegis/gm/2013/prt2761 19 11 2013.html

10. Pinto BK, Soares DC, Cecagno D, Muniz RM. Promoção da saúde e intersetorialidade: um processo em construção. Rev Min Enferm [serial on the internet]. 2012 [cited 2020 Aug 01];16(4):487-93. Available from: https://cdn. publisher.gn1.link/reme.org.br/pdf/v16n4a02. $p d f$

11. Spiegel J, Alegret M, Clair V, Pagliccia N, Martinez $B$, Bonet $M$, et al. Intersectoral action for health at a municipal level in Cuba. Int J Public Health [serial on the internet]. 2012 [cited 2020 Aug 01];57(1):1523. Available from: https://www.ncbi.nlm.nih.gov/ $\mathrm{pmc/articles/PMC3282006/pdf/382011}$ Article 279.pdf/?tool $=$ EBI 
12. Panader AT, Agudelo CNA, Bolívar SY, Cárdenas CLM. Tobacco control: an intersectorial experience in Tunja (Colombia). Gac Sanit [serial on the internet]. 2014 [cited 2020 Aug 01];28(6). Available from: https://sci-hub.tw/10.1016/j.gaceta.2014.05.012

13. Cardona Junior AHS, Andrade CWQ, Caldas LNM. Educação em saúde: programa e canal de comunicação via WhatsApp da unidade básica de saúde do N6 para comunidade rural do sertão pernambucano. APS Rev [serial on the internet]. 2020 [cited 2020 Aug 02];2(2):137-41. Available from: https:// apsemrevista.org/aps/article/view/92/63

14. Leite RAF, Brito ES, Silva LMC, Palha PF, Ventura CAA. Acesso à informação em saúde e cuidado integral: percepção de usuários de um serviço público. Interface (Bocutatu) [serial on the internet]. 2014 [cited 2020 Aug 02];18(51):661-71. Available from: https://www.scielo.br/pdf/icse/v18n51/1807-5762icse-1807-576220140653.pdf

15. Latgé PK, Araujo DN, Silva Junior AG. Comunicação, educação e vigilância popular em saúde em tempos de COVID-19 - a experiência das comunidades de Niterói, RJ. APS Rev [serial on the internet]. 2020 [cited 2020 Aug 2];2(2):122-27. Available from: https://apsemrevista.org/aps/article/view/110/61

16. Vilaça MLC. Cultura digital, conexões e conhecimentos. In: Lima JCP, organizador. Conectando patrimônios: pensando museus e educação. São Paulo: Pontocom; 2018. p. 93-104.

17. Brasil. Portaria $n^{\circ} 2.436$, de 21 de setembro de 2017. Aprova a Política Nacional de Atenção Básica, estabelecendo a revisão de diretrizes para a organização da Atenção Básica, no âmbito do Sistema Único de Saúde (SUS). Diário Oficial da União, Brasília (2017 Sept 21 [cited 2020 Aug 2]);Sec 1:68.

18. Morosini MV, Fonseca AF, Pereira IB. Educação em Saúde. In: Pereira IB, Lima JCF, organizadores. Dicionário da Educação Profissional em Saúde. Rio de Janeiro: EPSJV; 2008. p. 155-62.

19. Pierro B. Epidemia de Fake News. Pesq Fapesp [serial on the internet]. 2020 [cited 2020 Aug 02]. Available from: https://revistapesquisa.fapesp.br/ epidemia-de-fake-news/

20. Almeida MA. A promoção da saúde nas mídias sociais - Uma análise do perfil do Ministério da Saúde no Twitter [Trabalho de Conclusão de Curso]. Goiânia: Universidade Federal de Goiás; 2012.

21. França T, Rabello ET, Magnago C. As mídias e as plataformas digitais no campo da Educação Permanente em Saúde: debates e propostas. Saúde Debate [serial on the internet]. 2019 [cited 2020 July 22];43:106:15. Available from: https://scielosp.org/article/sdeb/2019. v43nspe1/106-115/
22. Freitas GM, Santos NSS. Atuação do enfermeiro na Atenção Básica de Saúde:Revisão integrativa de Literatura. Rev. Enferm. Cent.-0este Min [serial on the internet]. 2014 [cited 2020 Aug 02];4(2):1194-1203. Available from: http://www.seer.ufsj.edu.br/index. $\mathrm{php} / \mathrm{recom} /$ article/view/443

23. Mattos RA. Os sentidos da integralidade: algumas reflexões acerca de valores que merecem ser defendidos. In: Pinheiro R, Mattos RA, organizadores. 0 s sentidos da integralidade na atenção e no cuidado à saúde. Rio de Janeiro: Abertura; 2009. p. 43-68.

24. United Nations. Policy brief: COVID-19 and the need for action on mental health [document on the internet]. 2020 [cited 2020 Aug 05]. Available from: https://www.un.org/sites/un2.un.org/files/un policy brief-covid and mental health final.pdf

25. Fundação 0swaldo Cruz. Saúde Mental e Atenção Psicossocial na pandemia COVID-19. Rio de Janeiro: Ed. Fiocruz; 2020.

26. Ferreira C. Guia Para Atendimento Psicológico Online Durante a Pandemia [home-page on the internet] 2020 [cited 2020 Aug 06]. Available from: https://spsicologos.com/2020/04/07/guiapara-atendimento-psicologico-online-durante-apandemia/

27. Merhy EE. Saúde: a cartografia do trabalho vivo. 2. ed. São Paulo: Hucitec; 2005.
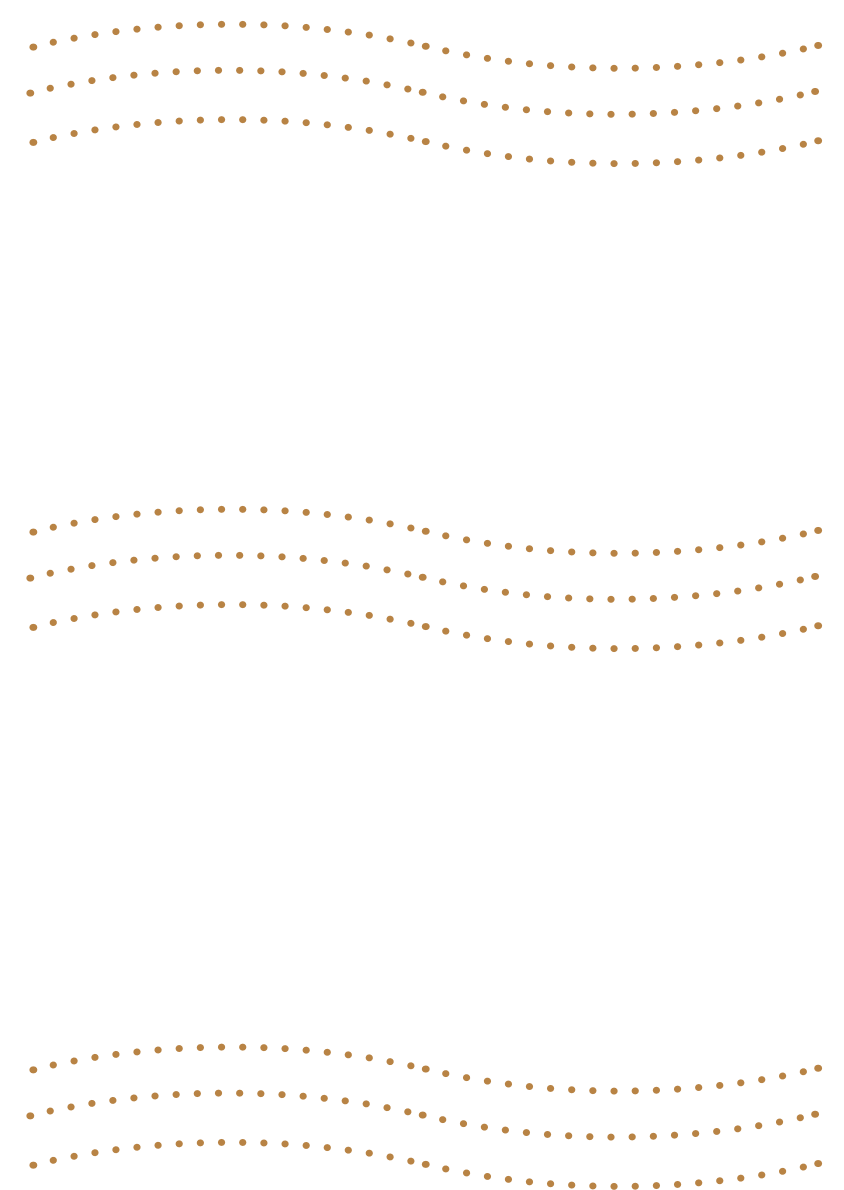